\title{
Program logic: a framework for health program design and evaluation - the Pap nurse in general practice program
}

\author{
Christine Mary Hallinan \\ Horsham Campus Research Precinct, University of Ballarat, Vic. 3400, Australia. \\ Email: c.hallinan@ballarat.edu.au
}

\begin{abstract}
In this paper, program logic will be used to 'map out' the planning, development and evaluation of the general practice Pap nurse program in the Australian general practice arena. The incorporation of program logic into the evaluative process supports a greater appreciation of the theoretical assumptions and external influences that underpin general practice Pap nurse activity. The creation of a program logic model is a conscious strategy that results an explicit understanding of the challenges ahead, the resources available and time frames for outcomes. Program logic also enables a recognition that all players in the general practice arena need to be acknowledged by policy makers, bureaucrats and program designers when addressing through policy, issues relating to equity and accessibility of health initiatives. Logic modeling allows decision makers to consider the complexities of causal associations when developing health care proposals and programs. It enables the Pap nurse in general practice program to be represented diagrammatically by linking outcomes (short, medium and long term) with both the program activities and program assumptions. The research methodology used in the evaluation of the Pap nurse in general practice program includes a descriptive study design and the incorporation of program logic, with a retrospective analysis of Australian data from 2001 to 2009. For the purposes of gaining both empirical and contextual data for this paper, a data set analysis and literature review was performed. The application of program logic as an evaluative tool for analysis of the Pap PN incentive program facilitates a greater understanding of complex general practice activity triggers, and also allows this greater understanding to be incorporated into policy to facilitate Pap PN activity, increase general practice cervical smear and ultimately decrease burden of disease.
\end{abstract}

\section{Background}

Cervical cancer is one of the most preventable and curable of all cancers, particularly if women are screened for precancerous cervical cells (Cuzick et al. 2000; Shafi and Welton 2007). Recent evidence has demonstrated that cervical cancer is in fact a rare outcome of persistent human papilloma virus (HPV) infection, and may take 10 or more years to develop even after cervical cells show precancerous changes (Walboomers et al. 1999; National Health and Medical Research Council 2006; Shafi and Welton 2007).

To date, research at a population level supports the viral causal theory for cervical cancer and demonstrates that HPV is a necessary cause in diagnosed cervical cancer (Franco et al. 1999; Walboomers et al. 1999; Bosch and de Sanjosé 2003; Clifford et al. 2003). Epidemiological data has also shown that over $95 \%$ of cervical cancers test positive for HPV DNA and $85 \%$ of individuals diagnosed with cervical cancer did not have a preventative screening test (Franco et al. 1999; Bosch and de Sanjosé 2003; Royal Australian College of General Practitioners 2009). The weight of this evidence strongly supports the population health benefits of cervical screening tests incorporated with early management of precancerous cervical changes.

In most developing countries, cervical cancer accounts for the greatest burden of disease caused by malignancies, and is the second most common cancer in females after breast cancer worldwide (Parkin et al. 2002; Bosch and de Sanjosé 2003). When comparing rates of cervical cancer in countries with similar cancer registration systems, Australia was found to have one of the lowest incidence of cervical cancer globally (Parkin et al. 2002; Australian Institute of Health and Welfare 2009a). This achievement has been largely attributed to the implementation of the National Cervical Screening Program (NCSP) initiated in 1991 in response to the inefficient ad hoc, opportunistic screening that had been available since the mid 1960s (National Health and Medical Research Council 2006). The main objective of the program was to reduce morbidity and mortality from cervical cancer by treating pre-cancerous lesions before progression to cancer. The screening program was developed and implemented by a range of stakeholders including general practitioners, women's health nurses, and national and state governments (National Health and Medical Research Council 2006). 
The NCSP consists of a coordinated approach to cervical screening where females between the ages of 18 and 20 years and up to the age of 69 are targeted, placed on a national register and recalled two yearly to participate in the program (Dickinson 2002; Department of Health and Ageing 2010a). Over the past two decades Australian population health data produced evidence of a significant decrease in the incidence of cervical cancers. The Australian Institute of Health and Welfare data demonstrated that the aged standardised incidence rate of cervical cancer in 2005 was almost half the rate recorded in 1998, with an incidence rate of 5.9 new cases per 100000 women in 2005 compared with a rate of 10.2 new cases per 100000 women in 1998 (Canfell et al. 2006; Australian Institute of Health and Welfare 2008). Since the implementation of the national screening program in 1991, participation rate data has been collected for evaluation; presently, cervical screening participation is estimated to be around 61\% (Australian Institute of Health and Welfare $2009 a$ ). This evaluation data indicated that over one-third of eligible Australian women have not been accessing the program, and also indicated that screening rates have not increased over the past 15 years since the establishment of the NCSP. In fact the national evaluation data not only reflected a plateau in national screening, but has also demonstrated a decline in the rate of screening from $64.8 \%$ in $1998-99$ to $60.6 \%$ in 2005-06 (Australian Institute of Health and Welfare 2002 , 2008). Qualitative research into cervical screen uptake barriers suggested that this static growth of cervical screening was a consequence of barriers that specifically related to the Pap screen activity in general practice. Contributing factors to Pap screen activity in the general practice domain included issues relating to general practitioner (GP) access, GP capacity limitations, GP workforce pressures as well as patient gender preferences (Young and Ward 2003; Christie et al. 2005; PapScreen Vic 2008).

In an attempt to address these barriers through the use of practice nurses (PNs), health policy makers developed general practice initiatives that provided funds to facilitate the development of the role of the practice nurse and build in capacity in the PN workforce. The financial initiatives aimed to increase the numbers of nurses working in general practice, increase the uptake of the Pap training courses by PNs and increase the number of Pap smears provided by credentialed PNs in general practice (Department of Health and Ageing 2005; McGoldrick et al. 2007). Explicitly, funding was allocated for the provision of scholarships to subsidise PN education and Pap training costs, as well as for the specific Medicare Benefits Schedule (MBS) nurse rebate for Pap screening activity undertaken by the PN for and on behalf of the GP (Australian Government 2005; Department of Health and Ageing 2006). In addition, a practice incentive payment (PIP) bonus was offered to general practices that demonstrated a commitment to increasing Pap screening rates and the utilisation of a practice nurse (Department of Health and Ageing 2008).

Despite these PN initiatives that commenced in 2001, evidence from general practice activity statistics demonstrate that credentialed Pap nurses continue to perform only a small proportion of all cervical screening tests in general practice (Australian Institute of Health and Welfare 2009b). General practice activity data also demonstrates that Pap activity contributes minimally to the total number of activities undertaken by nurses in general practice, as nationally PN Pap items account for less than $1.5 \%$ of all recorded nurse item numbers (Australian Institute of Health and Welfare 2009b). Interestingly data provided by the Victorian Cervical Cytology Registry indicates the number of Pap screens undertaken by nurses in all health arenas (general practice, community health and women's health clinics) has at least doubled over the last decade; however, nurses continue to be under represented as Pap test providers and currently contribute to $\sim 4.4 \%$ of all Pap tests performed in Victoria (Victorian Cervical Cytology Registry 2009). The national rate of PN Pap activity in general practice increased by $1.5 \%$ annually, from $0.6 \%$ in $2006-07$ to $0.9 \%$ in $2007-08$; however, the actual number of practice nurses engaging in Pap activity in general practice is in fact very small (Table 1) (Australian Institute of Health and Welfare 2009b).

\section{Purpose}

The purpose of this paper is to use program logic to evaluate the Pap nurse in general practice incentive program. The paper

Table 1. General practice activity in Australia from 199899 to 2007 08: 10-year data tables

Sources: Australian Institute of Health and Welfare 2009b. MBS, Medicare Benefits Schedule; N/A, not available

\begin{tabular}{|c|c|c|c|c|c|}
\hline \multirow{2}{*}{$\begin{array}{l}\text { Medicare } \\
\text { item } \\
\text { number }\end{array}$} & \multirow[t]{2}{*}{ Short descriptor } & \multicolumn{4}{|c|}{ Percentage of total $(95 \% \mathrm{CI})$} \\
\hline & & $\begin{array}{l}200506 \\
(n \quad 1696)\end{array}$ & $\begin{array}{l}200607 \\
\left(\begin{array}{ll}n & 1835\end{array}\right)\end{array}$ & $\begin{array}{l}200708 \\
\left(\begin{array}{ll}n & 2073\end{array}\right)\end{array}$ & $\begin{array}{r}200809 \\
(n \quad 2438)\end{array}$ \\
\hline 10993 & Immunisation & $69.5(63.875 .3)$ & $66.8(61.572 .2)$ & $64.1(59.6 \quad 68.6)$ & 63.6 \\
\hline 10996 & Wound treatment (other than normal aftercare) & $30.0(24.335 .7)$ & $32.6(27.240 .0)$ & $34.4(30.0 \quad 38.8)$ & 33.3 \\
\hline 10997 & $\begin{array}{l}\text { Service provided to a person with a chronic disease by a practice } \\
\text { nurse or registered Aboriginal Health Worker }\end{array}$ & N/A & N/A & $0.7(0.21 .2)$ & 1.9 \\
\hline 10994 & Cervical smear and preventive checks & $\mathrm{N} / \mathrm{A}$ & $0.2\left(\begin{array}{ll}0.0 & 0.5\end{array}\right)$ & $0.2\left(\begin{array}{ll}0.0 & 0.4\end{array}\right)$ & 0.7 \\
\hline 10995 & $\begin{array}{l}\text { Cervical smear and preventive checks: women aged } 2069 \text { years, } \\
\text { no smear in past } 4 \text { years }\end{array}$ & $\mathrm{N} / \mathrm{A}$ & $0.1\left(\begin{array}{ll}0.0 & 0.2\end{array}\right)$ & $0.1\left(\begin{array}{ll}0.0 & 0.2\end{array}\right)$ & 0.4 \\
\hline 10998 & Cervical smear & 0 & $0.1\left(\begin{array}{ll}0.0 & 0.3\end{array}\right)$ & $0.3\left(\begin{array}{ll}0.2 & 0.5\end{array}\right)$ & 0.1 \\
\hline 10999 & Cervical smear: women aged 2069 years, no smear in past 4 years & $0.5\left(\begin{array}{ll}0.0 & 0.9\end{array}\right)$ & $0.2\left(\begin{array}{ll}0.0 & 0.4\end{array}\right)$ & $0.3\left(\begin{array}{ll}0.0 & 0.8\end{array}\right)$ & 0 \\
\hline \multicolumn{2}{|c|}{ Total practice nurses activity with MBS item number allocation } & 100 & 100 & 100 & 100 \\
\hline
\end{tabular}


also demonstrates that the application of a logic model facilitates a greater understanding of the general practice barriers that impede PN Pap activity. Typically, evaluation of associations between 'cause and effect' in the health arena is problematic, as there is a tendency to emphasise what can be measured empirically, rather than study what may be important sociologically in the health care domain (Hay 2002; Brazil et al. 2005; Lewis 2005). The application of program logic to the Pap nurse in general practice incentive program not only enables the program to be represented as a framework map, but also importantly articulates the theoretical assumptions (albeit sound or flawed) that underpin the decisions made by policy makers and programmers. The use of program logic promotes the clarification of (visible and invisible) linkages between health professionals, consumers and funders, and facilitates the recognition of the complex relationships between players in the general practice arena. The model also provides a visualisation of incremental changes and allows a schematic overview of the Pap PN incentive program at work. Through the application of an evaluative tool such as program logic, both drivers and barriers to Pap nurse activities are articulated with enhanced clarity (Fig. 1).

\section{What is program logic?}

'Program logic is a programs theory of action; it is a theory about the causal linkages among the various components of a program: it links resources and activities with outputs and outcomes' (Funnell 1997, p. 5). The complexities that underpin causal relationships are incorporated into program logic; program logic models not only map out direct causal links in a program, but also depict the assumptions that influence a program's components (Taylor-Powel et al. 2002; Brazil et al. 2005). Although effects and outcomes are typically related to specific events in a program, other factors also contribute to outcomes such as the program's context, process and properties. The nature of the relationships between these other factors ultimately effect the anticipated or expected causal relationship. Causal relationships are rarely as simple as the 'if-then' relationship suggests, rather they consist of multiple interactions that result in feedback loops with consequences such as delays and program modifications (Funnell 1997; Taylor-Powel et al. 2002).

\section{The program logic model}

Program logic models are diagrammatic representations that 'plot out' the complex iterative causal mechanisms that

\section{PROGRAM LOGIC MODEL}

GOALS

The use of the Nurse in General Practice will increase Pap screen uptake in General Practice in females between the ages of 18 and 69 years. SITUATION

- Since the implementation of the National Cervical Screening Program in 1991 screening participation rates have remained static (61\% of female population between 18 and 69 years)

- Barriers to cervical screening in General Practice include GP accessibility; GP workforce; GP capacity; gender preference; age of practitioner preferences, culture and language

- Incentives to promote the use of the Practice Nurse to perform Pap screening in General Practice were initiated in 2004.

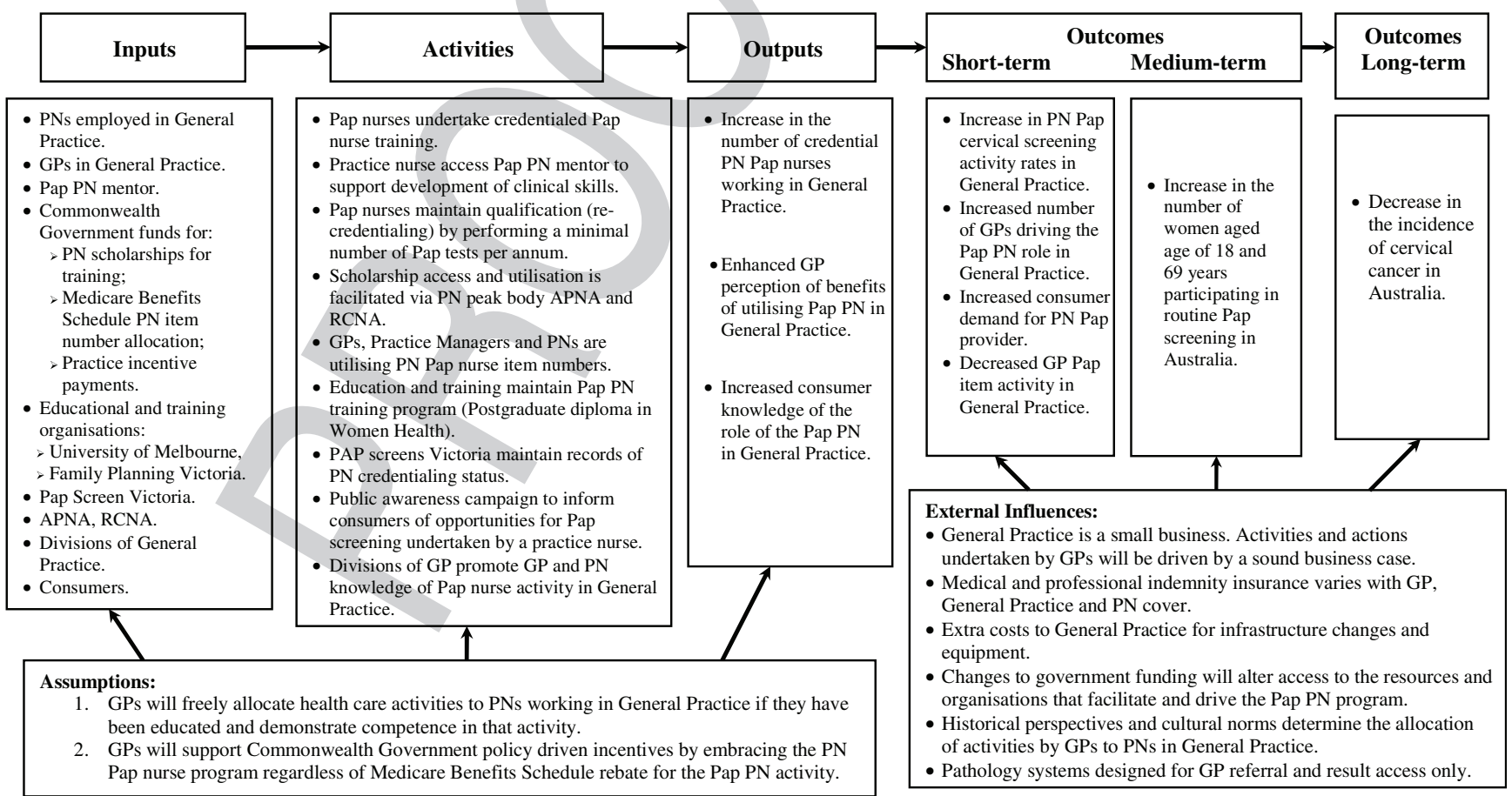

Q3 Fig. 1. Program logic model. APNA, Australian Practice Nurse Association; GP, general practitioner; PN, practice nurse; RCNA, Royal College Nursing Australia. 
underpin program design, implementation and evaluation (Owen 2006). A simple but well developed model is like a useful roadmap: it defines boundaries, highlights important features and shows clearly marked 'pathways' (Kellogg Foundation 2004). Program logic models assist in maintaining a balanced focus on the big picture, the component parts and importantly illustrate the assumed causal connections (The Health Communications Unit 2001; Kellogg Foundation 2004; Owen 2006). The process of developing a program logic model is a conscious process that results in the creation of an explicit understanding of the challenges ahead, the resources available and time frames for outcomes (Owen 2006).

Logic models help to:

- clarify expected linkages;

- tease out underlying assumptions;

- focus on principles to test;

- educate program funders and policy makers;

- move programs into the action and learning stages (TaylorPowel et al. 2002).

Q1 The basic logic model (Fig. 2) consists of component parts that flow from inputs to outcomes.

\section{Research methodology}

The research methodology used in the evaluation of the Pap nurse in general practice program includes the incorporation of program logic evaluation and the use of a descriptive study design, with a retrospective analysis of Australian data from 2001 to 2009. For the purposes of gaining both empirical and contextual data for this paper, a dataset analysis and literature review was performed. Australian Commonwealth and State Government websites were searched including the Department of Health and Ageing, Australian Institute of Health and Welfare, and the National Health and Medical Research Council Victorian Cervical Cytology Register. Boolean searches were undertaken in databases (CINHAL, Pub Med, MEDITEXT and APA-FT) with words and phrases such as cervical screening, pap nurse program, general practice initiatives, pap screen uptake, practice nurse, general practice nurses, cervical screening in general practice, national cervical screening program, human papillomavirus, cervical carcinoma, general practice incentives, program logic, health program evaluation and evaluation.

The descriptive study design integrates the use of secondary sources, and includes analysis of existing Australian datasets and a literature review. Program logic guides evaluation through the identification of key program elements followed by the articulation of how these elements are expected to relate to each other (Cooksy et al. 2001). In this application of program logic to the Pap nurse program, quantitative data is analysed against the hypothetical program logic framework for the purpose of measurement of intended results against the actual outcomes. The inclusion of qualitative contextual evidence incorporates a connection of program evaluation to social science theory and facilitates the development of theory driven knowledge, where the assumptions and external influence that confound the cause and effect relationship are made more explicit (Cooksy et al. 2001).

\section{Program logic and the Pap nurse incentive program}

The program logic model developed for the PN Pap incentive program is a tool supporting the conceptualisation of PN pap activity for both the measurement and evaluation of PN Pap activity outcomes. It communicates the intent of the incentive program to Pap program stakeholders such as GPs, PNs, governments and policy makers. The application of the logic model an evaluative tool identifies uncertainties or 'weak links' in the Pap nurse in general practice initiative. Through the early identification of these uncertainties, qualitative and empirical data gained from further clarificative evaluation illuminates barriers to Pap nurse activity and enables faulty assumptions to be addressed. Analysis of the logic map illustrates how inputs are linked to the activities that are required to drive the program; analysis also provides opportunities for program remodelling and ultimately program improvement. It demonstrates how the access of capital such as Commonwealth Government program funding; practice nurse workforce support; general practice incentive payments; practice nurse education and practice infrastructure can facilitate change, and maintain the momentum needed to operate the program. The use of program logic to evaluate outcomes against inputs within the general practice context, not only justifies and validates the Commonwealth Government resources that have already been funded by the Pap incentive program, but also supports a case for ongoing funding provision or conversely funding withdrawal.

\section{Discussion}

In the case of the Pap nurse in general practice initiative, the actual potential of program logic in the evaluation rests on the early identification of uncertainties, as well as the articulation of rigorous well-founded assumptions. If faulty assumptions

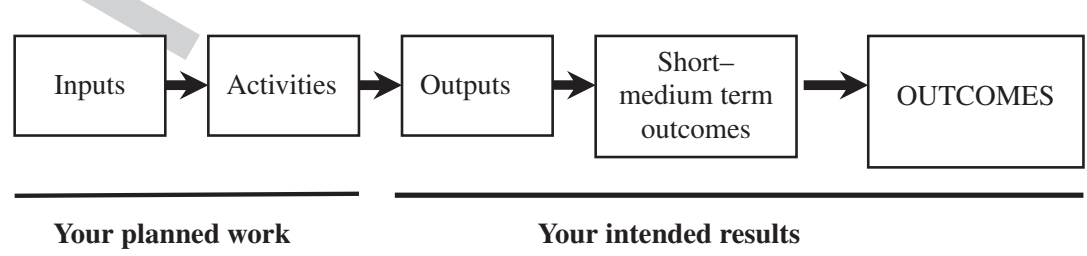

Fig. 2. The basic logic model source. Adapted from the basic logic model (Kellogg Foundation 2004, p. 1). 
are allowed to persist and uncertainties are not clarified, then the reality, context and structure of the general practice program may be significantly misrepresented in the PN Pap logic model. The assumptions embedded in the PN Pap program logic model that are presented in this paper demonstrate how unsound theory undermines the expected PN incentive program outcomes (Fig. 1). The two main assumptions underpinning the general practice PN Pap program are: (i) GPs will freely allocate health care activities to practice nurses working in general practice if they have been educated and demonstrate competence in that activity; and (ii) GPs will support policy driven incentives by embracing the PN Pap nurse program regardless of the MBS PN rebate (Fig. 1). Yet the drivers for PN Pap testing allocation by GPs do not rest solely on PN competency nor do they rest on PN capacity or scope of practice; the drivers are very much influenced by the complex contextual and structural features of Australian general practice domain.

Challenges to the PN Pap program include influences from general practice structure and context that controls practice nurse activity. As previously stated it would fair to assume that if there was capacity within a trained and credentialed nursing workforce to undertake Pap activity in general practice, then the Pap activity would be freely allocated to the nursing workforce, yet as is clearly evident in the general practice nurse activity datasets, this is not the case (Australian Institute of Health and Welfare 2009b). Factors such as the general practice business case, professional indemnity, infrastructure costs and pathology 'red tape' have been described as barriers to the uptake of the Pap nurse MBS item in general practice (Jasiak and Passmore 2007; Keleher et al. 2007).

Other factors influencing Pap PN outcomes is general practitioner self-determination and professional autonomy, where the GP independently decides 'what activities are done' and 'who does what' in the general practice domain. General practice is a small business, and the general practitioner is commonly the small business owner and as a consequence, practice nurse task allocation is frequently determined by financial triggers and the general practice business case (Foley et al. 2004). As the practice 'gatekeeper' the GP not only determines PN task allocation, but has exclusive access to MBS item remuneration as well (Table 2). To incorporate into initiatives a greater understanding of the general practitioner 'gatekeeper' role, policy makers and programmers need to also acknowledge the inter-professional dynamic that influences the general practice health care team.
A significant amount of Commonwealth Government funding has supported and continues to support the Pap nurse incentive through the provision of subsidised training, and general practice PIP payments. However, inexplicably the MBS remuneration for PN cervical smear activity in general practice is only one-third of the GP remuneration for an identical Pap activity (Department of Health and Ageing $2010 b$ ). The MBS rebate for Pap test provision by a nurse in general practice is $\$ 11.25$ - (Item 10998) and Pap test with a preventative check is $\$ 22.70$ - (Item 10994) compared with the MBS general practitioner rebate of $\$ 34.30$ - (Item 23) and $\$ 65.20$ - (Item 36) respectively (Department of Health and Ageing 2010b). It is likely that these inequitable Medicare rebates act as contributing factors that impede PN Pap activity, as would lack of reimbursement for costs associated with PN Pap activity, such as costs for infrastructure changes to the general practice itself and the purchase of additional equipment. These fiscal disincentives are compounded by professional indemnity insurance anomalies where there is a potential for gap in coverage, which may increase the risk of litigation claims made against GPs for activities performed by a nurse. Further disincentives include pathology barriers that are a consequence of pathology systems that were originally designed for exclusive general practitioner access (referral, collection and results). Through the incorporation of judicious consideration by policy makers that financial triggers are 'activity' drivers in the general practice arena, the MBS rebate for Pap smear tests when undertaken by a nurse should be determined to be at least equal to, if not more than, the remuneration for Pap test when undertaken by a GP. An increased MBS remuneration for Pap nurse activity would facilitate the uptake of the Pap nurse MBS item and would also provide a recompense for the general practice in lieu of the financial and administrative burdens imposed by the PN Pap incentive program itself.

Additional factors that influence the Pap nurse incentive program include the sociological constructs relating to the general practice arena and the concept of medical dominance (Mills and Hallinan 2009). The 'social world' of general practice is underpinned by the complex relationships between the GP and the PN. The complexities of these relationships are based on professional domains, power imbalances, general practice ownership, history, culture and tradition, as well as the politics of health service provision (Lewis 2005; Mills and Hallinan 2009). These multifaceted inter-professional associations influence outcomes in all health initiatives

Table 2. Australian Medical Association (2006) position statement on primary health care

\footnotetext{
-3.3 As ownership and make-up of general practices changes, clinical sovereignty of general practitioners must continue to be a core, non-negotiable principle of the Australian health care system.

- 4.2 Internationally, there is an increasing emphasis on the importance of general practitioners as lynchpins in the health system. . and are therefore recognised as crucial stakeholders in the delivery of agreed national policy. . GPs play a crucial role as 'gateways' to the rest of the medical system: in this role they have a profound influence on both health outcomes and health expenditures

- 10.7 Remuneration of primary care activities must be for the service provided at the GP's instigation, not based on who provided the service. This will allow the general practitioner to determine which member of the primary care team is best placed to provide the care and the patient to access the care they need and deserve.
} 
directed at general practices in Australia (Watts et. al. 2004; Lewis 2005; Mills and Hallinan 2009). It is essential that the contextual 'social world' of general practice is acknowledged by policy makers, bureaucrats and program designers when they attempt to address through policy, issues relating to access, equity and accessibility of health initiatives.

\section{Implications for policy makers}

As governments drive health programs through the domain of general practice, the professional autonomy and selfdetermination of the medical profession must be considered as a factor that affects the potential for a program's success. The use of a sound program logic model supports the articulation and clarification of assumptions and external influences. This articulation enables strategies to be built into the program to focus on the contextual and structural factors in the general practice arena that underpin outcomes. It is now time for governments, policy makers, bureaucrats and programmers to acknowledge the complexities inherent in the general practice domain. It is now also time for the Pap nurse in general practice initiatives to be remodelled so that actions, resources and incentives will tackle the parts of general practice that impede Pap nurse activity.

\section{Conclusion}

This paper does not claim to provide a panacea to general practice Pap nurse barriers, nor does it attempt to deliver an alternative program. However, it does provide the reader with insights into the world of general practice through the use of a logic map to create an increased awareness of the content, contexts and constructs in the general practice arena. The application and analysis of program logic to the Pap PN incentive program enables a greater understanding of complex general practice activity triggers, and also allows this greater understanding to be incorporated into policy to facilitate Pap PN activity, increase general practice cervical smear participation and ultimately reduce the burden of disease.

\section{Conflicts of interest}

None declared.

\section{References}

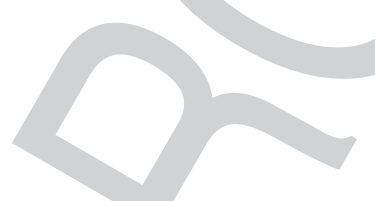

Australian Government (2005) Federal Budget 2005 2006. Rebate for Pap smears taken in rural Australia: Australian Government Budget 200506. Commonwealth of Australia, Canberra. Available at http://www.budget. gov.au/2005-06/ministerial/html/dotars-11.htm [Verified 10 September 2008]

Australian Institute of Health and Welfare (2002) Cervical screening in Australia 1998 1999. AIHW Cat. No. 16. Available at http://www.aihw. gov.au/publications/can/csa98-99/csa98-99.pdf [Verified 20 September 2009]

Australian Institute of Health and Welfare (2008) Cervical screening in Australia 2005 2006. AIHW Cat. No. CAN 41. Available at http://www. aihw.gov.au/publications/can/csa05-06/ [Verified 20 September 2009]

Australian Institute of Health and Welfare (2009a) Cervical screening in Australia 2006 2007. AIHW Cat. No. CAN 43. Available at http://www. aihw.gov.au/publications/index.cfm/title/10676 [Verified 8 March 2010]
Australian Institute of Health and Welfare (2009b) General practice activity in Australia 199899 to 2007 08: 10 year data tables. AIHW Cat. No. GEP 25. Available at http://www.aihw.gov.au/publications/gep/gep-2511013/gep-25-11013-c13.pdf [Verified 20 September 2009]

Australian Medical Association (2006) AMA primary health care position statement 2006. Australian Medical Association. Available at http:// www.ama.com.au/node/2502 [Verified 28 September 2010]

Bosch XF, de Sanjosé S (2003) Chapter 1: human papillomavirus and cervical cancer burden and assessment of causality. Journal of the National Cancer Institute. Monographs 31, 313.

Brazil K, Ozer E, Cloutier MM, Levine R, Stryer D (2005) From theory to practice: improving the impact of health services research. BMC Health Services Research 5, 1. doi:10.1186/1472-6963-5-1

Canfell K, Sitas F, Beral V (2006) Cervical cancer in Australia and the United Kingdom: comparison of screening policy and uptake, and cancer incidence and mortality. The Medical Journal of Australia 185, 482486.

Christie L, Gamble J, Creedy D (2005) Women's views of registered nurses as Papanicolau smear providers'. Contemporary Nurse 20, 160168.

Clifford GM, Smith JS, Plummer M, Muñoz N, Franceschi S (2003) Human papillomavirus types in invasive cervical cancer worldwide: a meta-analysis. British Journal of Cancer 88, 63 73. doi:10.1038/ sj.bjc. 6600688

Cooksy LJ, Gill P, Kelly A (2001) The program logic model as an integrative framework for a multimethod evaluation. Evaluation and Program Planning 24, 119 128. doi:10.1016/S0149-7189(01)00003-9

Cuzick J, Sasieni P, Davies P, Adams J, Normand C, Frater A, van Ballegooijen M, van den Akker-van Marle E (2000) A systematic review of the role of human papillomavirus (HPV) testing within a cervical screening programme: summary and conclusions. British Journal of Cancer 83, 561 565. doi:10.1054/bjoc.2000.1375

Department of Health and Ageing (2005) Medicare Australia: MBS items $(10998,10999)$ for Pap smears taken by a practice nurse in a regional, rural or remote area. Australian Government, Canberra. Available at http:// www.medicareaustralia.gov.au/provider/incentives/files/mbs items for pap smears nov 2005.pdf [Verified 10 October 2009]

Department of Health and Ageing (2006) Medicare Australia: MBS items $(10998,10999)$ for Pap smears taken by a practice nurse on behalf of a medical practitioner. Australian Government, Canberra. Available at http://www.nevdgp.org.au/files/practicesupport/practicemanagernurse support/MBS\%20items $\% 20$ for $\% 20$ Pap $\% 20$ smears $\% 20$ in $\% 20$ all $\% 20$ areas-\%20Nov\%2006.pdf [Verified 11 September 2009]

Department of Health and Ageing (2008) Practice incentives program. Australian Government, Canberra. Available at http://www.medicare australia.gov.au/provider/incentives/index.jsp [Verified 14 September 2009]

Department of Health and Ageing (2010a) National cervical screening program. Australian Government, Canberra. Available at http://www. Q2 health.gov.au/internet/screening/publishing.nsf/Content/cervical-about [Verified 1 September 2009]

Department of Health and Ageing (2010b) Medicare Benefits Schedule: MBS on line. Australian Government, Canberra. Available at http:// www9.health.gov.au/mbs/search.cfm?q 10998\&sopt I [Verified 11 April 2010]

Dickinson JA (2002) Cervical screening: time to change the policy. The Medical Journal of Australia 176, 547550.

Foley E, Hutchinson R, Pascoe T, Snowdon T, Watts I, Whitecross L (2004) General practice nursing in Australia RCNA/RACGP nursing in general practice project. Available at http://www.rcna.org.au/pages/practiceproj. php [Verified 10 September 2009]

Franco EL, Rohan TE, Villa LL (1999) Epidemiologic evidence and human papillomavirus infection as a necessary cause of cervical cancer. Journal of the National Cancer Institute 91, 506 511. doi:10.1093/jnci/91.6.506

Funnell S (1997) Program logic: an adaptable tool for designing and evaluating programs. Evaluation News and Comment 6, 517. 
Hay C (2002) 'Political analysis: a critical introduction.' (Palgrave, Macmillan: Hampshire)

Jasiak S, Passmore E (2007) Enhancing the roles of practice nurses: outcomes of cervical screening education and training in NSW barriers. The Australian Journal of Advanced Nursing 27, 4045.

Keleher H, Joyce C, Parker R, Piterman L (2007) Practice nurses in Australia: current issues and future directions. The Medical Journal of Australia 187, 108110.

Kellogg Foundation (2004) 'Logic model development guide.' (W. K. Kellogg Foundation: Michigan) Available at http://www.publichealth. vic.edu.au/current/economics/upload/05b-kellogg-foundation-logicmodel-development-guide.pdf [Verified 10 October 2008]

Lewis, J (2005) 'Health policy and politics: networks, ideas and power.' (IP communications: East Hawthorn)

McGoldrick M, Crawford M, Peers M (2007) Cervical screening in general practice strategies for improving participation. Australian Family Physician 36, 183184.

Mills J, Hallinan C (2009) The social world of Australian practice nurses and the influence of medical dominance: an analysis of the literature. International Journal of Nursing Practice 15, 489 494. doi:10.1111/ j.1440-172X.2009.01772.x

National Health and Medical Research Council (2006) Screening to prevent cervical cancer: guidelines for the management of asymptomatic women with screen-detected abnormalities. Reference No. WH39. Available at http://www.nhmrc.gov.au/PUBLICATIONS/synopses/wh39syn.htm [Verified 14 September 2009]

Owen J (2006) 'Program evaluation: forms and approaches.' 4th edn. (Allen and Unwin: Crows Nest)

PapScreen Vic (2008) Barriers to screening for women, Pap Screen Victoria. Available at http://www.papscreen.org.au/browse.asp?ContainerID c14 [Verified 14 September 2009]

Parkin D, Bray F, Ferlay J, Pisani P (2002) Global cancer statistics 2002. International Agency for Research on Cancer, GLOBOCAN, Lyon. Available at http://caonline.amcancersoc.org/cgi/reprint/55/2/74 [Verified 14 September 2009]
Royal Australian College of General Practitioners (2009) 'Guidelines for preventative activities in general practice.' 7 th edn. Available at http://www.racgp.org.au/Content/NavigationMenu/ClinicalResources/ RACGPGuidelines/eRedBook/redbook 7th edition May 2009.pdf [Verified 20 September 2009]

Shafi M, Welton K (2007) Colposcopy and cervical intraepithelial neoplasia. Obstetrics, Gynaecology and Reproductive Medicine 17, 106180.

Taylor-Powel E, Jones L, Henert E (2002) Enhancing program performance with logic models. Available at http://www1.uwex.edu/ces/lmcourse [Verified 9 September 2009]

The Health Communications Unit (2001) 'Logic models workbook version 6.' (Centre for Health Promotion, University of Toronto: Canada) Available at http://www.thcu.ca/infoandresources/publications/ logicmodel.wkbk.v6.1.full.aug27.pdf [Verified 14 September 2008]

Victorian Cervical Cytology Registry (2009) Evaluation of Pap tests collected by nurses in Victoria during 2009. Victorian Cervical Cytology Registry. Available at http://www.vccr.org/downloads/VCCR Nurses report 2009.pdf [Verified 13 March 2010]

Walboomers JM, Jacobs MV, Manos MM, Bosch FX, Kummer JA, Shah KV, Snijders PJ, Peto J, Meijer CJ, Muńoz N (1999) Human papillomavirus is a necessary cause of invasive cervical cancer worldwide. The Journal of Pathology 189, 12 19. doi:10.1002/(SICI)1096-9896(199909)189:1< $12::$ AID-PATH431>3.0.CO;2-F

Watts I, Foley E, Hutchinson R, Pascoe T, Whitecross L, Snowdon T (2004) General practice nursing in Australia RCNA/RACGP nursing in general practice project. Available at http://www.rcna.org.au/pages/practiceproj. php [Verified 20 September 2009]

Young J, Ward J (2003) Randomised trial of intensive academic detailing to promote opportunistic recruitment of women to cervical screening by general practitioners. Australian and New Zealand Journal of Public Health 27, 273 281. doi:10.1111/j.1467-842X.2003.tb00394.x

Manuscript received 28 September 2009, accepted 14 October 2010 
